\title{
In-silico Antimalarial Study of Monocarbonyl Curcumin Analogs and Their 2,4-Dinitro Phenylhydrazones Using the Inhibition of Plasmepsin II as Test Model
}

\author{
Olatomide A. Fadare ${ }^{1, *}$, Ezekiel O.Iwalewa ${ }^{2}$, Craig A. Obafemi ${ }^{1}$, Feyisola P. Olatunji ${ }^{3}$ \\ ${ }^{1}$ Department of Chemistry, Obafemi Awolowo University, Ile-Ife, Nigeria \\ ${ }^{2}$ Department of Pharmacology, University of Ibadan, Ibadan, Nigeria \\ ${ }^{3}$ Department of Chemistry, Washington State University, Pullman, U.S.A. \\ *Corresponding author: tomidefadare2000@yahoo.com
}

\begin{abstract}
A well-known component of the Indian spice turmeric, curcumin, has received a lot of attention in recent years as a potential antimalarial agent but the inherent problems associated with low bioavailabilty tends to limit its applicability. The bioavailability is linked to its low solubility in water and its rapid break down in the blood plasma. In this study, we have proposed the use of synthetic analogs of curcumin and their derivatives which are expected to be less prone to degradation in the blood plasma as possible antimalarials. The binding affinity of monocarbonyl analogs of curcumin and their 2,4-dinitrophenylhydrazone derivatives for the chain A domain of plasmepsin II, one of the key enzymes involved in hemoglobin digestion in the food vacuole of the malaria parasite was determined by computational docking analysis, performed using Auto Dock Vina 1.1.2, pymol and Chem 3D ultra 12.0. The binding energies of the 20 compounds studied was compared with that of pepstatin A (a known inhibitor of plasmepsin II), curcumin and chloroquine. The 3D structure of the protein was obtained from the protein data bank (PDB ID:1M43), the compounds' 3D structure was generated with the Chem 3D ultra 12.0 and visualization done with pymol. Out of the 20 compounds docked with plasmepsin II, 17 had binding energies higher than that of pep $\mathrm{A}(-32.6, \mathrm{~kJ} / \mathrm{mol})$ and 19 of the compounds had binding energies higher than that of curcumin $(30.96$, $\mathrm{kJ} / \mathrm{mol})$. The docked compounds, $5 \mathrm{~b}, 6 \mathrm{~b}$ and $7 \mathrm{~b}$ had the highest binding energies $(-44.73 \mathrm{~kJ} / \mathrm{mol},-42.64 \mathrm{~kJ} / \mathrm{mol}$ and $41.80 \mathrm{~kJ} / \mathrm{mol}$ respectively). It is expected that the compounds with binding energies higher than that of pep A may be considered for further antimalarial studies in-vitro and in-vivo.
\end{abstract}

Keywords: monocarbonyl curcumin analog, 2,4-dinitrophenyl hydrazone, low bioavailability, plasmepsin II, pepstatin $A$

Cite This Article: Olatomide A. Fadare, Ezekiel O.Iwalewa, Craig A. Obafemi, and Feyisola P. Olatunji, "In-silico Antimalarial Study of Monocarbonyl Curcumin Analogs and Their 2,4-Dinitro Phenylhydrazones Using the Inhibition of Plasmepsin II as Test Model." American Journal of Pharmacological Sciences, vol. 5, no. 2 (2017): 18-24. doi: 10.12691/ajps-5-2-1.

\section{Introduction}

Resistance to the most widely used antimalarial drug, chloroquine, has increased continuously in recent years; it is now estimated that failure rates for chloroquine are as high as $50-60 \%$ in East and Central Africa. Failure rates for treatment with other prevalent drugs, sulfadoxine-pyremethamine and mefloquine, are also increasing [1]. The malaria causing organism, plasmodium's ability to adapt in the face of selective pressure brought on by drug treatment has thus helped establish an environment in which novel drugs against additional targets are in constant need. The continued search for new molecular targets for drug design is expected to broaden the therapeutic arsenal and strategies to fight drug resistance in human malaria. Curcuminoids have been reported to have a prominent antimalarial activity both in-vitro (against chloroquine resistant and sensitive plasmodium falciparum laboratory strains) and in-vivo (against plasmodium berghei) studies $[2,3,4,5]$. In 2005 , it was first observed that curcumin has antimalarial activity [5], Nandakumar and co-researchers [4], also discovered in 2006 that curcumin has a synergistic effect when used in combination with artemisinin, specifically, the combination was effective in preventing parasite recrudescence. In a study involving plasmodium berghei. It was also observed that curcumin was a potent inhibitor of chloroquine resistant P. falciparum. Curcumin itself has low bioavailability especially when administered orally which is an intrinsic problem of the curcumin that may prevent it from becoming a first line antimalarial drug. This low bioavailability is attributed to its high rate of metabolism and its rapid eliminaton [6,7]. Different attempts have been made using different models such as encapsulations in nanoparticles [8,9] nanoemulsions [10,11], cyclodextrins [12], phospholipid complexes [13] or solid dispersions [14] all in a bid to improve the oral bioavailability and therapeutic efficacy of curcumin [15]. 
However, these strategies are characterized by several weaknesses, such as high costs, cytotoxicity, limited drug loading and entrapment efficiency, poor scale-up and the use of organic solvents. The bioavailability may be increased as a result of cooking or dissolution in oil [16]. Recently, self-emulsifying lipid-based systems were investigated as agents to solubilize the hydrophobic curcumin in the gastro-intestinal tract and to protect curcumin from enzymatic and/or chemical hydrolysis in order to improve the oral bioavailability of curcumin $[17,18,19]$. One of the factors that contribute to its low bioavailability is its rapid breakdown in the blood plasma via a retro-aldol reaction of the 1,3-dicarbonyl moiety of the molecule. A viable solution to the inherent problem of bioavailability of curcumin as an antimalarial agent which has not been explored yet is synthetic modification. Analogs of curcumin which will not breakdown readily in the blood plasma may be synthesized and screened for possible antimalarial activity. Monocarbonyl curcumins (synthetic analogs of curcumin) have been proposed to be studied in this work. The monocarbonyl curcumins are devoid of the $\mathrm{CH} 2 \mathrm{CO}$ group that is implicated in the retro-aldol breakdown of curcumin in the blood plasma (Figure 1).

It is thought that if the analogs of curcumin are more bioavailable and have considerable antimalarial activity then they will be better candidates for future development as antimalarial agents. Hemoglobin $(\mathrm{Hb})$ digestion occurs within a highly specialized Plasmodium compartment referred to as the food vacuole (FV), which presents an acidic $\mathrm{pH}(5.0-5.4)$ and contains proteases responsible for $\mathrm{Hb}$ digestion [20]. These proteases include four aspartic proteases (plasmepsins) [21,22,23], three cysteine proteases (falcipains) [24,25,26,27], a metalloprotease (falcilysin) [28] and a dipeptidyl aminopeptidase 1 (DAPP1) [29]. The early events of hemoglobin degradation in the FV involve two closely related aspartic proteases from $\mathrm{P}$. falciparum. Both proteases, termed plasmepsin (plm) I and II, hydrolyze the peptide bond between residues Phe33 and Leu34 in the apha-chain of native hemoglobin, thus initiating hemoglobin degradation $[30,31,32]$. This initial cleavage most likely promotes protein unfolding and release of the heme moiety followed by futher degradation by the plms, the cysteine protease falcipain, and the metalloprotease falcilysin [33,34]. It has also been established that [35], plm II is capable of degrading erythrocyte skeleton components spectrin, actin, and protein 4.1 at neutral $\mathrm{pH}$ and used specific antibodies to localize plm II to the periphery of the parasite during the merozoite stage, implying that plm II plays a role in mature merozoite escape from the erythrocyte host by cytoskeletal degradation [36]. Plasmepsin II (plm II) is the most extensively characterized of these enzymes since several crystal structures have been determined $[37,38,39]$ and potent inhibitors developed $[40,41,42,43,44]$. Silva et al. [37] determined the first crystal structure of the plm family showing recombinant plm II complexed with pepstatin A, a known aspartic protease inhibitor whose inhibition constant for plm II is $0.006 \mathrm{nM}$. The structure of plm II has the typical bilobal shape and topology of eukaryotic aspartic proteases. Two topologically similar $\mathrm{N}$ - and C-terminal domains contact each other along the bottom of the binding cleft that contains the catalytic dyad
(Asp34 and Asp214). The presence of two plm II molecules in the crystallographic asymmetric unit suggested a high degree of interdomain flexibility of plm II, which was later confirmed by the resolution of different enzyme-inhibitor complexes. Many experimental peptidic and nonpeptidic plm inhibitors exist and have been described in detail, along with their $\mathrm{K} i$ values and often the steps of their synthesis, in a number of papers [37], [45-66]. Some of these inhibitors were identified by high-throughput screening $[61,67,68,69,70]$, by computational analysis of the plm's active site $[56,62]$, or in natural products $[57,71,72]$, though most are the result of rational drug design.

\section{Materials and Methods}

A set of 10 monocarbonyl curcumins along with their dinitrophenylhydrazone derivatives were docked with plm II in this study using autodock vina to estimate the binding energies of the compounds with plmII. The results were compared with that of curcumin docked with plm II under the same conditions. The monocarbonyl curcumins are bis benzylidene propanones thought to be easily synthesized from a Claisen-Schmidt condensation of 1 mole of acetone with two molar equivalents of an aromatic aldehyde (Figure 2). The dinitro phenylhydrazones are derivatives of the monocarbonyl curcumins analogs that are supposedly synthesized from the condensation of the monocarbonyl curcumins with 2,4-dinitrophenylhydrazine (Figure 3). The 3D structures of the compounds were prepared using chem3D and their energies were minimized with MM2 Force Field of Chem3D application interface and the ligands were saved as pdb files. MGL Tools 1.5.4 was used to prepare the ligands' pdbqt files, setting the number of rotatable bonds to maximum, since most of the mono carbonyl used in this study have fewer than eight rotatable bonds. 3D crystallographic structure of the plasmepsin II cocrystallized with pepstatin A - was obtained from the protein data bank (PDB ID: 1M43). PyMol was used to remove one of the dimeric chains and the pepstatin A molecule bound to it. Water molecules were also removed. The polypeptide chain was processed in MGL Tools 1.5.4 to obtain the grid.pdbqt files. The grid box of the macromolecule was obtained based on the binding site of plm II to the inhibitor, pepstatin A, in the downloaded PDB file. The grid box dimension in Amstrong units is $(x, y, z)=(14,20,16)$ and centred at coordinates $(\mathrm{x}, \mathrm{y}, \mathrm{z})=(55,62,26)$ The dockings were performed using Auto Dock Vina 1.1.2 which is a new generation of docking software from the Molecular Graphics Lab [73].

\section{Results}

In order to check the accuracy of the Vina docking program, we have docked the plmII cocrystallized ligand, pepstatinA (pepA) into the plmII binding site. The docking results were satisfactory when we analysed the root mean square deviation values (RMSd), which showed lower values (i.e RMSd $<3 \AA$ ), despite the different binding modes. 
<smiles>COc1cc(/C=C/C(=O)CCCC(=O)/C=C/c2ccc(O)c(OC)c2)ccc1O</smiles>

Group present in curcumin that is absent in the monocarbonyl curcumin analogs<smiles>COc1cc(/C=C/C(=O)/C=C/c2ccc(O)c(OC)c2)ccc1O</smiles>

A monocarbonyl curcumin devoid of the $\mathrm{CH}_{2} \mathrm{CO}$ group that is part of the curcumin's 1,3-dicarbonyl group implicated in the retro-aldol breakdown of curcumin in the blood plasma

Figure 1. Comparison of curcumin with its monocarbonyl curcumin analog

la<smiles>O=C(/C=C/c1ccccc1)/C=C/c1ccccc1</smiles>

2a<smiles>COc1cc(/C=C/C(=O)/C=C/c2ccc(O)c(OC)c2)ccc1O</smiles>

3a<smiles>COc1ccc(/C=C/C(=O)/C=C/c2ccc(OC)cc2)cc1</smiles>

$4 a$<smiles>O=C(/C=C/c1ccccc1O)/C=C/c1ccccc1O</smiles>

$5 a$<smiles>O=C(/C=C/c1cccc2ccccc12)/C=C/c1cccc2ccccc12</smiles>

6a<smiles>O=C(/C=C/c1cc2ccccc2nc1Cl)/C=C/c1cc2ccccc2nc1Cl</smiles>

$7 \mathrm{a}$<smiles>O=C(/C=C/c1ccccc1[N+](=O)[O-])/C=C/c1ccccc1[N+](=O)[O-]</smiles>

$8 \mathrm{a}$<smiles>COc1cc(/C=C/C(=O)/C=C/c2cc(OC)c(OC)c(OC)c2)cc(OC)c1OC</smiles>

$9 \mathrm{a}$<smiles>COc1ccc(/C=C/C(=O)/C=C/c2ccc(OC)c(OC)c2)cc1OC</smiles>

$10 \mathrm{a}$<smiles>O=C(/C=C/c1cccnc1)/C=C/c1cccnc1</smiles>

Figure 2. The structures of the monocarbonyl curcumin analogs of curcumin docked with plasmepsin II<smiles>[R]c1ccc(/C=C/C(=O)/C=C/c2ccc([R])cc2)cc1</smiles>

la-10a

$$
\text { 2,4-dinitro phenylhydrazine }
$$<smiles>[R]c1ccc(/C=C/C(/C=C/c2ccc([R])cc2)=NNc2ccc([N+](=O)[O-])cc2[N+](=O)[O-])cc1</smiles>

lb-10b dinitro phenylhydrazone of monocarbonvl curcumin

Figure 3. The condensation of the monocarbonyl curcumins with 2,4-dinitro phenylhydrazine to generate the corresponding 2,4-dinitro phenylhydrazones of the monocarbonyl curcumin analogs 
Table 1. Autodock Vina Score of Ligands with PImII, The Number of Hydrogen Bond Interactions and Amino Acid Residues Interacting in The Binding Site Via H-Bonding.

\begin{tabular}{|c|c|c|c|}
\hline Compounds & Vina Score $\left(\mathrm{kJmol}^{-1}\right)$ & Number of H-bonds & Residues of the PImII binding site interacting with the ligands \\
\hline Chloroquine & -28.42 & 2 & Ser79, Asp214 \\
\hline Pepstatin A & -32.66 & 7 & Ser79, Ser118, Tyr192, Gly216 \\
\hline Curcumin & -30.96 & 3 & Ser218, Ala219 \\
\hline $1 \mathbf{a}$ & -33.02 & 0 & - \\
\hline $1 \mathbf{b}$ & -39.29 & 4 & Ser79, Thr217, Ser218, Thr221 \\
\hline $2 a$ & -32.60 & 2 & Ser79, Leu131 \\
\hline $2 \mathbf{b}$ & -36.78 & 4 & Ser79, Tyr192, Asp214, Thr221 \\
\hline 3a & -32.19 & 0 & - \\
\hline 3b & -37.62 & 4 & Ser79, Ser218, Thr221 \\
\hline $4 \mathbf{a}$ & -32.60 & 0 & - \\
\hline $4 \mathbf{b}$ & -39.29 & 6 & Tyr192, Asp214, Thr217, Ser218 \\
\hline $5 \mathbf{a}$ & -39.71 & 0 & - \\
\hline $5 \mathbf{b}$ & -44.73 & 3 & Tyr192, Asp214, Thr217 \\
\hline 6a & -36.78 & 0 & - \\
\hline $\mathbf{6 b}$ & -42.64 & 4 & Ser79, Ser118, Tyr192, Gly216 \\
\hline $7 a$ & -33.86 & 5 & Ser79, Ser218, Ala219 \\
\hline $7 \mathbf{b}$ & -41.80 & 7 & Asn76, Ser79, Thr217, Ser218 \\
\hline $8 \mathbf{8 a}$ & -30.10 & 2 & Ser118, Thr217 \\
\hline $8 \mathbf{b}$ & -32.60 & 5 & Ser79, Tyr192, Asp214, Ser218, Thr221 \\
\hline 9a & -30.51 & 2 & Ser79, Tyr192 \\
\hline $9 \mathbf{b}$ & -35.11 & 3 & Ala38, Ser79, Tyr192 \\
\hline 10a & -29.76 & 0 & - \\
\hline 10b & -37.20 & 3 & Ser79, Gly 216, Thr221 \\
\hline
\end{tabular}

The results of docking studies using the AutoDock Vina scores observed for plmII and the 20 curcuminoids and their derivatives are summarized in Table 1 . The output binding energy is in $\mathrm{kcal} / \mathrm{mol}$ which has been converted to $\mathrm{kJ} / \mathrm{mol}$. Table 1 shows the number of hydrogen bond interractions between the ligand of the highest pose scores and the amino acids residues in the binding cavity, with residues Ser79, Tyr192, Asp214, and Ser218 appearing consistently in the conformational poses of protein-ligand complex. In all the docking runs, the DNP derivatives showed higher binding energies compared to the monocarbonyl curcumin counterparts (Figure 3).

The DNP derivatives are much larger than their parent monocarbonyl curcumin analogs, hence, it is expected that they possess a higher magnitude of van der Waal contribution to the binding energies. These derivatives also possess extra polar groups $\left(-\mathrm{NO}_{2}\right.$ groups) that augment the $\mathrm{H}$-bond interractions in the binding site.

\section{Discussion}

Amongst the ligand with the highest binding affinities, $\mathbf{5 b}, \mathbf{6 b}$ and $\mathbf{7 b}$ appears to show the highest interaction energies. The set of compounds with the highest binding energies are $\mathbf{5 b}(-44.73 \mathrm{~kJ} / \mathrm{mol}), 6 \mathbf{b}(-42.64 \mathrm{~kJ} / \mathrm{mol})$, $7 \mathbf{b}(-41.80 \mathrm{~kJ} / \mathrm{mol}), \mathbf{5 a}(-39.71 \mathrm{~kJ} / \mathrm{mol}), \mathbf{4 b} \boldsymbol{\&} \mathbf{1 b}(-39.29$ $\mathrm{kJ} / \mathrm{mol}$ ). Compounds $\mathbf{5 b}, \mathbf{6 b}, \mathbf{7 b}$ and $\mathbf{1 0 b}$ are the largest molecules in the compound set used in this study, hence, it is expected that since they fit into the binding pocket, they will elicit the largest hydrophobic interactions, which results to a substantial increasing in their binding energies. These compounds also form H-bond interactions with the residues Ser79, Tyr192, Asp214 and Ser218 in the binding pocket. Figure 4 shows the binding interaction of the compounds $\mathbf{5 b}$ and $\mathbf{6 b}$ in the plmII. It is notable that compound $\mathbf{6 b}$ has $\mathrm{H}$-bonds with exactly the same amino acid residues as pepstatin A, Ser79, Ser118, Tyr192, Gly216.

(a)

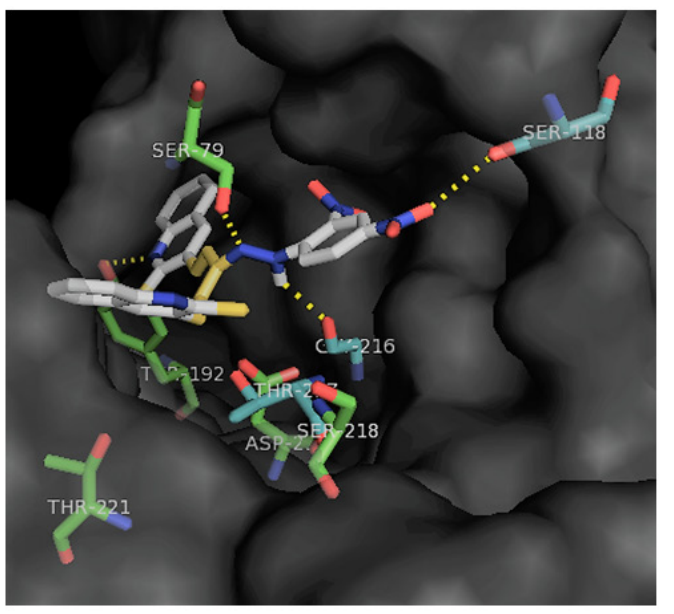

(b)

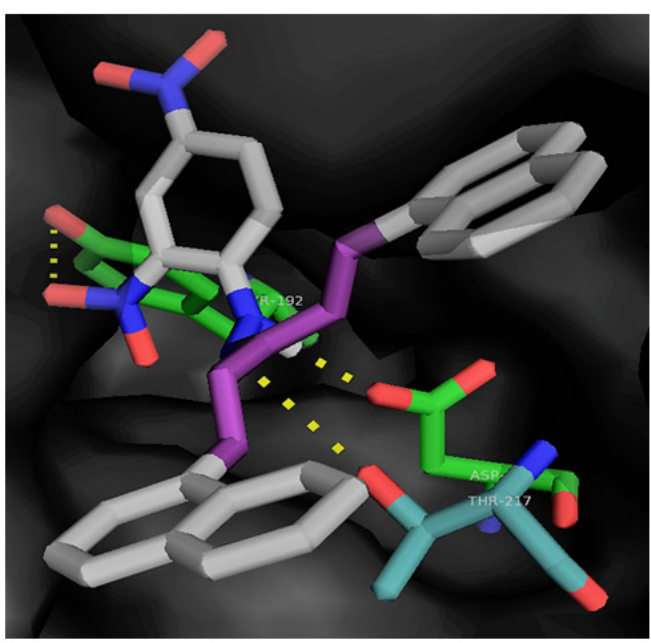

Figure 4. The structures of compounds $\mathbf{6 b}$ (a) and $\mathbf{5 b}$ (b) docked with plasmepsin II showing the amino acid residues interacting by H-bonding 


\section{Conclusion}

Most of the compounds investigated in this study have a higher binding affinity compared to that of pepA for the plm II except compounds $\mathbf{2 a}, \mathbf{3 a}$ and $\mathbf{4 a}$ which are slightly less but comparable. The test compounds having a higher binding affinity gives insight into the extent to which the compounds might inhibit the enzyme plmII and therefore disrupt its metabolic function within the parasite and ultimately culminate in antimalarial activity. Most of the compounds docked with plmII have better binding profiles than curcumin and the high binding energies of the docked compounds reveal that these set of compounds include some that have high binding affinity for the plmII and interact by $\mathrm{H}$-bonding with similar amino acid residues as pepA. These compounds may be good candidates for further exploration as antimalarial-plmII inhibitors. Of particular interest are the compounds $7 \mathbf{b}(-41.8 \mathrm{~kJ} / \mathrm{mol}, 7 \mathrm{H}$-bonds) that has as many $\mathrm{H}$-bonding interactions as pepstatin $\mathrm{A}$ ($32 \mathrm{~kJ} / \mathrm{mol}, 7 \mathrm{H}$-bonds) and much higher binding energy compared to that of pepA, compound $\mathbf{6 b}(-42.64 \mathrm{~kJ} / \mathrm{mol})$ that interacts by $\mathrm{H}$-bonding with the same residues as pepA but having a higher binding energy relative to that of pepA and compound $\mathbf{5 b}$ that has the highest binding energy $(-44.73 \mathrm{~kJ} / \mathrm{mol})$. If the monocarbonyl curcumin analogs and their derivatives have good oral absorption and are stable in the blood plasma, with the high binding affinity observed for some of these compounds for one of the key metabolic enzymes of the malaria parasite, then these class of compounds may have potential as lead compounds for the discovery of a new antimalarial drug.

\section{References}

[1] W.H.O. (2010) World Malaria Report 2010. Available at: http://www.who.int/malaria/world_malaria_report_2010/worldmal ariareport2010.pdf. Accessed: March/2011.

[2] Mishra, K., Dash A.P., Swain B.K., Dey N., "Anti-malarial activities of Andrographis paniculata and Hedyotis corymbosa extracts and their combination with curcumin" Malar. J., 8: 26, 2009.

[3] Mulabagal V., Calderon A.I., "Development of binding assays to screen ligands for Plasmodium falciparum thioredoxin and glutathione reductases by ultrafiltration and liquid chromatography/mass spectrometry" J. Chromatogr. B Analyt. Technol. Biomed. Life Sci., 878: 987-93, 2010.

[4] Nandakumar, D.N., Nagaraj, V.A., Vathsala, P.G., Rangarajan, P., Padmanaban G. "Curcumin-artemisinin combination therapy for malaria" Antimicrob. Agents Chemother. 50 (2006) 1859-60.

[5] Reddy R.C., Vatsala P.G., Keshamouni V.G., Padmanaban G., Rangarajan P.N. "Curcumin for malaria therapy". Res. Biochem. Biophys Commun.; 326: 472-4, 2005.

[6] Aggarwal B.B., Sundaram C., Malani N., Ichikawa H. "Curcumin: The Indian Solid Gold". Adv. Exp. Med. Biol, 595: 1-75, 2007.

[7] Anand P., Kunnumakkara A.B., Newman R., Aggarwal B.B. "Bioavailability of Curcumin: Problems and Promises". Molecular Pharmaceutics; 4(6): 807-18. 2007

[8] Nayak A.P., Tiyaboonchai W., Patankar S., Madhusudhan B., Souto E.B., "Curcuminoids Loaded Lipid Nanoparticles: Novel Approach Towards Malaria Treatment" Colloids Surf. B: Biointerfaces, 81: 263-73, 2010.

[9] Akhtar F., Rizvi M.M., Kar S.K. "Oral Delivery of Curcumin Bound to Chitosan Nanoparticles Cured Plasmodium yoelii Infected Mice" Biotechnol. Adv; 30: 310-20, 2012.

[10] Ahmed K., Li Y., McClements D.J., Xiao H. "Nanoemulsion - and Emulsion-based Delivery Systems for Curcumin: Encapsulation and Release properties" Food Chem, 132: 799-807, 2012.
[11] Yu, H., Huang. Q. "Improving the Oral bioavailability of Curcumin Using Novel Organogel-based Nanoemulsions". J. Agric. Food Chem; 60: 5373-9, 2012.

[12] Desai, K. Curcumin Cyclodextrin Combination for Preventing or Treating Various Diseases. Patent US 2010/0779103.

[13] Maiti, K., Mukherjee, K., Gantait A, Saha B.P., Mukherjee P.K. "Curcumin Phospholipid Complex: Preparation, Therapeutic Evaluation and Pharmacokinetic Study in Rats". Int. J. Pharm; 330: 155-63, 2007.

[14] Seo, S.W., Han, H.K., Chun M.K., Choi, H.K. "Preparation and Pharmacokinetic Evaluation of Curcumin Solid Dispersion using Solutol HS15 as a Carrier". Int. J. Pharm; 424: 18-25, 2012.

[15] Yallapu, M.M., Jaggi, M., Chauhan S.C. "Curcumin Nano formulations: A Future Nanomedicine for Cancer". Drug Discov. Today; $17:$ 71-81, 2012.

[16] Marczylo T.H., Verschoyle, R.D., Cooke D.N., Morazzoni, P., Steward, W.P., Gescher, A.J. "Comparison of Systemic Availability of Curcumin with that of Curcumin Formulated with Phosphatidylcholine" Cancer Chemotherapy and Pharmacology; 60(2): 171-7, 2007.

[17] Cui, J., Yu, B., Zhao, Y., Zhu, W., Li, H., Lou, H., Zhai, G. "Enhancement of Oral Absorption of Curcumin by Selfmicroemulsifying Drug Delivery Systems" Int. J. Pharm; 371: $148-55,2009$

[18] Setthacheewakul, S., Mahattanadul, S., Phadoongsombut N., Pichayakorn, W., Wiwattanapatapee, R., "Development and Evaluation of Self-microemulsifying Liquid and Pellet Formulations of Curcumin, and Absorption Studies in Rats" Eur. J. Pharm. Biopharm; 76: 475-85, 2010.

[19] Yan T.D., Kim, J.A., Kwak, M.K., Yoo, B.K., Yong C.S., Choi, H.G. "Enhanced oral Bioavailability of Curcumin via a Solid Lipid-based Self-emulsifying Drug Delivery System Using a Spray-drying Technique”. Biol. Pharm. Bull; 34: 1179-86, 2011.

[20] Banerjee R., Liu, J., Beatty, W., Pelosof, L., Klemba, M. and Goldberg D.E. "Four plasmepsins are active in the Plasmodium falciparum food vacuole, including a protease with an active-site histidine". Proceedings of the National Academy of Sciences of the United States of America; 99: 990-95, 2002.

[21] Gluzman, I.Y., Francis, S.E., Oksman, A., Smith, C.E., Duffin, K.L. and Goldberg, D.E. "Order and specificity of the Plasmodium falciparum hemoglobin degradation pathway". Journal of Clinical Investigation; 93(4): 1602-08, 1994.

[22] Dame, J.B., Reddy, G.R., Yowell, C.A., Dunn, B.M., Kay, J. and Berry, C. "Sequence, expression and modelled structure of an aspartic proteinase from the human malaria parasite:Plasmodium falciparum". Molecular and Biochemical Parasitology. vol. 64, no. 2, pp. 177-90. 1994.

[23] Humphreys M.J., Moon, R.P., Klinder A. et al. "The aspartic proteinase from the rodent parasite Plasmodium berghei as a potential model for plasmepsins from the human malaria parasite, "Plasmodium falciparum". FEBS Letters; 463(1-2): 43-8, 1999.

[24] Salas, F., Fichmann, J., Lee, G.K., Scott, M.D. and Rosenthal P.J. "Functional expression of falcipain, a Plasmodium falciparum cysteine proteinase, supports its role as a malarial hemoglobinase". Infection and Immunity; 63(6): 2120-2125, 1995.

[25] Sijwali, P.S., Kato, K., Seydel K.B. et al. "Plasmodium falciparum cysteine protease falcipain-1 is not essential in erythrocytic stage malaria parasites". Proceedings of the National Academy of Sciences of the United States of America; 101(23): 8721-26, 2004.

[26] Shenai, B.R., Sijwali, P.S., Singh, A. and Rosenthal, P.J., "Characterization of native and recombinant falcipain-2, a principal trophozoite cysteine protease and essential hemoglobinase of Plasmodium falciparum". Journal of Biological Chemistry; 275(37): 29000-010, 2000.

[27] Sijwali, P.S., Shenai, B.R., Gut, J., Singh, A. and Rosenthal, P.J. "Expression and characterization of the Plasmodium falciparum haemoglobinase falcipain-3". Biochemical Journal; 360(2): 481-89, 2001.

[28] Eggleson, K.K., Duffin, K.L. and Goldberg, D.E. "Identification and characterization of falcilysin, a metallopeptidase involved in hemoglobin catabolism within the malaria parasite Plasmodium falciparum”. Journal of Biological Chemistry; 274(45): 32411-417. 1999.

[29] Klemba, M., Gluzman, I. and Goldberg, D.E., “A Plasmodium falciparum dipeptidyl aminopeptidase I participates in vacuolar hemoglobin degradation". Journal of The Biological Chemistry; 279(41): 43000-007. 2004. 
[30] Gluzman, I.Y., Francis, S.E., Oksman, A., Smith, C.E., Duffin, K.L and Goldberg, D.E. "Order and specificity of the Plasmodium falciparum haemoglobin degradation pathway". The Journal of Clinical Investigation; 93: 1602-08.1994.

[31] Goldberg, D.E., Slater, A.F., Beavis, R., Chait, B., Cerami A. and Henderson, G.B. "Hemoglobin degradation in the human malaria pathogen Plasmodium falciparum: a catabolic pathway initiated by a specific aspartic protease" The Journal of Experimental Medicine; 173: 961-69.1991

[32] Goldberg, D.E. "Hemoglobin degradation in Plasmodium-infected red blood cells". Seminars in Cell Biology; 4: 355-61, 1993.

[33] Eggleson, K.K., Duffin, K.L. and Goldberg, D.E. "Identification and characterization of falcilysin, a metallopeptidase involved in haemoglobin catabolism within the malaria parasite Plasmodium falciparum". The Journal of Biological Chemistry; 274: 32411-17, 1991.

[34] Francis, S.E., Gluzman, I.Y., Oksman, A., Banerjee D. and Goldberg, D.E. "Characterization of native falcipain, an enzyme involved in Plasmodium falciparum hemoglobin degradation". Molecular and Biochemical Parasitology; 83: 189-200. 1996.

[35] Le Bonniec, S., Deregnaucourt, C., Redeker, V., Banerjee, R., Grellier, P., Goldberg D.E. and Schrevel. J. "Plasmepsin II, an acidic hemoglobinase from the Plasmodium falciparum food vacuole, is active at neutral $\mathrm{pH}$ on the host erythrocyte membrane skeleton". The Journal of Biological Chemistry; 274: 14218-223. 1999.

[36] Blackman, M.J. "Malarial proteases and host cell egress: an 'emerging' cascade". Cellular Microbiology; 10: 1925-34. 2008.

[37] Silva A.M., Lee, A.Y., Gulnik, S.V., Maier, P., Collins, J., Bhat, T.N., Collins, P.J., Cachau, R.E., Luker, K.E., Gluzman, I.Y., Francis, S.E., Oksman, A., Goldberg, D.E., and Erickson, J.W. "Structure and inhibition of plasmepsin II, a hemoglobindegrading enzyme from Plasmodium falciparum". Proceedings of the National Academy of Sciences of the United States of America; 93(19): 10034-39.1996.

[38] Asojo, O.A., Gulnik, S.V., Afonina, E. et al. "Novel uncomplexed and complexed structures of plasmepsin II, an aspartic protease from Plasmodium falciparum" Journal of Molecular Biology; 327(1), 173-81. 2003.

[39] Asojo, O.A., Afonina, E., Gulnik S.V. et al. "Structures of ser205 mutant plasmepsin II from Plasmodium falciparum at $1.8 \mathrm{~A}$ in complex with the inhibitors rs367 and rs370." Acta Crystallographica Section D; 58(12); 2001-008. 2002

[40] Boss, C., Richard-Bildstein, S., Weller T. et al. "Inhibitors of the Plasmodium falciparum parasite aspartic protease plasmepsin II: as agents". Current Medicinal Chemistry; 10: 883-907. 2003.

[41] Ersmark, K., Feierberg, I., Bjelic S. et al. "C-symmetric inhibitors of Plasmodium falciparum plasmepsin II: synthesis and theoretical predictions". Bioorganic and Medicinal Chemistry; 11(17): 3723-33. 2003.

[42] Ersmark, K., Feierberg, I., Bjelic S. et al. "Potent inhibitors of the Plasmodium falciparum enzymes plasmepsin I and II devoid of cathepsin D inhibitory activity". Journal of Medicinal Chemistry; 47(1): 110-122.

[43] Kiso, A., Hidaka, K., Kimura T. et al. "Search for substrate based inhibitors fitting the S2' space of malarial aspartic protease plasmepsin II". Journal of Peptide Science; 10(11): 641-47. 2004.

[44] Ersmark, K., Samuelsson, B. and Hallberg, A. "Plasmepsins as potential targets for new antimalarial therapy". Medicinal Research Reviews; 26(5): 626-66. 2006

[45] Rosenthal, P.J. "Plasmodium falciparum: effects of proteinase inhibitors on globin hydrolysis by cultured malaria parasites" Experimental Parasitology; 80: 272-81. 1995.

[46] Francis, S.E, Gluzman, I.Y., Oksman, A., Knickerbocker, A., Mueller, R., Bryant, M.L., Sherman, D.R., Russell D.G., Goldberg, D.E. Molecular characterization and inhibition of a Plasmodium falciparum aspartic hemoglobinase. The EMBO Journal 1994; 13: 306-17.

[47] Nezami, A., Kimura, T., Hidaka, K., Kiso, A., Liu, J., Kiso, Y., Goldberg, D.E., Freire, E. "High-affinity inhibition of a family of Plasmodium falciparum proteases by a designed adaptive inhibitor". Biochemistry; 42, 8459-64. 2003.

[48] Wyatt, D.W. and Berry, C. "Activity and inhibition of plasmepsin IV, a new aspartic proteinase from the malaria parasite, Plasmodium falciparum" FEBS Letters; 513: 159-62. 2002.

[49] Westling, J., Yowell, C.A., Majer, P., Erickson, J.W., Dame J. and Dunn, B.M. "Plasmodium falciparum, P. vivax, and P. malariae: a comparison of the active site properties of plasmepsins cloned and expressed from three different species of the malaria parasite" Experimental Parasitology ; 87: 185-93.1997.

[50] Prade, L., Jones, A.F., Boss, C.R., Bildstein, S. Meyer, S., Binkert, C. and Bur, D. "X-ray structure of plasmepsin II complexed with a potent achiral inhibitor". The Journal of Biological Chemistry; 280: 23837-843, 2005.

[51] Johansson, P.O., Lindberg, J., Blackman, M.J., Kvarnstrom, I., Vrang, L., Hamelink, E., Hallberg, A., Rosenquist A. and Samuelsson, B., "Design and synthesis of potent inhibitors of plasmepsin I and II: X-ray crystal structure of inhibitor in complex with plasmepsin II". Journal of Medicinal Chemistry; 48: 4400-09. 2005.

[52] Bjelic, S., Nervall, M., Gutierrez-deTeran, H., Ersmark, K., Hallberg A. and Aqvist, J. "Computational inhibitor design against malaria plasmepsins". Cellular and Molecular Life Sciences; 64: 2285-2305. 2007

[53] Azim, M.K., Ahmed, W., Khan I.A., Rao N.A. and Khan, K.M. "Identification of acridinyl hydrazides as potent aspartic protease inhibitors". Bioorganic \& Medicinal Chemistry Letters; 18: 3011-15.2008.

[54] Blum, A., Bottcher, J., Sammet, B., Luksch, T., Heine, A., Klebe, G., Diederich, W.E. "Achiral oligoamines as versatile tool for the development of aspartic protease inhibitors". Bioorganic \& Medicinal Chemistry 16: 8574-86. 2008.

[55] Cunico, W., Gomes, C.R., Facchinetti, V., Moreth, M., Penido, C., Henriques, M.G., Varotti, F.P., Krettli, L.G., Krettli, A.U, da Silva, F.S., Caffarena E.R. and de Magalhaes, C.S. "Synthesis, antimalarial evaluation and molecular modeling studies of hydroxyl ethylpiperazines, potential aspartyl protease inhibitors, part 2". European Journal of Medicinal Chemistry; 44: 3816-20. 2009.

[56] Degliesposti, G., Kasam, V., Da Costa, A., Kang, H.K., Kim, N., Kim, D.W., Breton, V., Kim D. and Rastelli, G. "Design and discovery of plasmepsin II inhibitors using an automated workflow on largescale grids". ChemMedChem; 4: 1164-73. 2009.

[57] Fah, C., Hardegger, L.A., Baitsch, L., Schweizer, W.B., Meyer S., Bur, D. and Diederich F. "New organofluorine building blocks: inhibition of the malarial aspartic proteases plasmepsin II and IV by alicyclic alpha,alpha-difluoroketone hydrates". Organic and Biomolecular Chemistry; 7: 3947-57. 2009.

[58] Friedman R. and Caflisch, A. "Discovery of plasmepsin inhibitors by fragment-based docking and consensus scoring". ChemMedChem; 4: 1317-26. 2009.

[59] Hidaka, K., Kimura, T., Ruben, A.J., Uemura, T., Kamiya, M., Kiso, A., Okamoto, T., Tsuchiya, Y., Hayashi, Y., Freire, E. and Kiso, Y. "Antimalarial activity enhancement in hydroxymethylcarbonyl (HMC) isosterebased dipeptidomimetics targeting malarial aspartic protease plasmepsin". Bioorganic \& Medicinal Chemistry 2008; 16: 10049-60.

[60] Janka, L., Clemente, J., Vaiana, N., Sparatore, A., Romeo S. and Dunn, B.M. "Targeting the plasmepsin 4 orthologs of Plasmodium sp. with "double drug" inhibitors". Protein and Peptide Letters; 15 : 868-73. 2008

[61] Kasam, V., Salzemann, J., Botha, M., Dacosta, A., Degliesposti, G., Isea, R., Kim, D., Maass, A., Kenyon, C., Rastelli, G., Hofmann-Apitius M., and Breton, V. "WISDOM-II: screening against multiple targets implicated in malaria using computational grid infrastructures". Malaria Journal; 8: 88. 2009.

[62] Luksch, T., Chan, N.S., Brass, S., Sotriffer, C.A., Klebe G. and Diederich, W.E. "Computer-aided design and synthesis of nonpeptidic plasmepsin II and IV inhibitors". ChemMedChem; 3: 1323-36. 2008.

[63] Nguyen, J.T., Hamada, Y., Kimura, T. and Kiso, Y. "Design of potent aspartic protease inhibitors to treat various diseases". Archiv der Pharmazie; 341: 523-35. 2008.

[64] Orrling, K.M., Marzahn, M.R., Gutierrezde-Teran, H., Aqvist, J., Dunn, B.M. and Larhed, M. "Alpha-Substituted norstatines as the transition-state mimic in inhibitors of multiple digestive vacuole malaria aspartic proteases". Bioorganic \& Medicinal Chemistry; 17: 5933-49. 2009.

[65] Ramirez, A.R., Guerra, Y., Otero, A., Garcia, B., Berry, C., Mendiola, J., Hernandez-Zanui, A., Chavez Mde, L. "Generation of an affinity matrix useful in the purification of natural inhibitors of plasmepsin II, an antimalarial-drug target”. Biotechnology and Applied Biochemistry 2009; 52: 149-57.

[66] Rumsh, L.D., Mikhailova, A.G., Mikhura, I.V., Prudchenko, I.A., Chikin, L.D., Mikhaleva, I.I., Kaliberda, E.N., Dergousova, N.I., 
Mel'nikov E.E. and Formanovskii, A.A "Selective inhibitors of plasmepsin II from Plasmodium falciparum based on pepstatin". Bioorganicheskaia Khimiia; 34: 739-46. 2009.

[67] Jiang, S., Prigge, S.T., Wei, L., Gao, Y., Hudson, T.H., Gerena, L., Dame J.B. and Kyle, D.E. "New class of small nonpeptidyl ompounds blocks Plasmodium falciparum development in vitro by inhibiting plasmepsins". Antimicrobial Agents and Chemotherapy; 45: 2577-84. 2001

[68] Weik, S., Luksch, T., Evers, A., Bottcher, J., Sotriffer, C.A., Hasilik, A., Loffler, H.G., Klebe G. and Rademann, J. "The potential of P1 site alterations in peptidomimetic protease inhibitors as suggested by virtual screening and explored by the use of C-C-coupling reagents". ChemMedChem; 1: 445-57. 2006.

[69] Carroll C.D. and Orlowski, D. "Screening aspartyl proteases with combinatorial libraries". Advances in Experimental Medicine and Biology; 436: 375-80. 1998.
[70] Flotow, H., Leong C.Y. and Buss, A.D. "Development of a plasmepsin II fluorescence polarization assay suitable for high throughput antimalarial drug discovery". Journal of Biomolecular Screening; 7: 367-371. 2002.

[71] Dell'Agli, M., Galli, G.V., Corbett, Y., Taramelli, D., Lucantoni, L., Habluetzel, A., Maschi, O., Caruso, D., Giavarini, F., Romeo, S., Bhattacharya D. and Bosisio, E. "Antiplasmodial activity of Punica granatum L. fruit rind". Journal of Ethology; 125: 279-85. 2009.

[72] Dell'Agli, M., Galli, G.V., Parapini, S., Basilico, N., Taramelli, D., Said, A., Rashed K. and Bosisio, E. "Antiplasmodial activity of Ailanthus excels". Fitoterapia; 79: 112-16. 2008.

[73] Trott, O., Olson, A.J. "AutoDock Vina: improving the speed and accuracy of docking with a new scoring function, efficient optimization and multithreading" Journal of Computational Chemistry; 31: 455-61. 2010. 